\title{
Erratum to: Toolkit for Counseling Spanish-SpeakingClients
}

Lorraine T. Benuto

\section{Erratum to:}

L.T. Benuto (ed.), Toolkit for Counseling Spanish-Speaking Clients, https://doi.org/10.1007/978-3-319-64880-4

The affiliations of the authors of this chapter (Rebecca M. Pasillas and Darisabel Roman Laureano) has changed and the same has been updated:

\section{Rebecca M. Pasillas}

Department of Psychology, The University of Texas at El Paso

and

\section{Darisabel Roman Laureano}

Department of Psychiatry, Texas Tech University Health Sciences Center at El Paso 